\title{
BMJ Open Non-conveyance in the ambulance service: a population-based cohort study in Stockholm, Sweden
}

\author{
Jakob Lederman (1) ,1,2 Veronica Lindström, ${ }^{3,4}$ Carina Elmqvist, ${ }^{5,6}$ \\ Caroline Löfvenmark, ${ }^{7}$ Therese Djärv ${ }^{8}$
}

To cite: Lederman J, Lindström V, Elmqvist C, et al. Non-conveyance in the ambulance service: a population-based cohort study in Stockholm, Sweden. BMJ Open 2020;10:e036659. doi:10.1136/ bmjopen-2019-036659

- Prepublication history and additional material for this paper are available online. To view these files, please visit the journal online (http://dx.doi. org/10.1136/bmjopen-2019036659).

Received 24 December 2019

Revised 10 March 2020

Accepted 09 June 2020

Check for updates

(C) Author(s) (or their employer(s)) 2020. Re-use permitted under CC BY-NC. No commercial re-use. See rights and permissions. Published by BMJ.

For numbered affiliations see end of article.

Correspondence to

Jakob Lederman;

jakob.lederman@ki.se

\section{ABSTRACT}

Objectives Non-conveyed patients represent a significant proportion of all patients cared for by ambulance services in the western world. However, scientific knowledge on non-conveyance is sparse. Therefore, the aim of this study was to describe the prevalence of non-conveyance, investigate associations and compare patients' characteristics, drug administration, initial problems and vital signs between non-conveyed and conveyed patients. Design A population-based retrospective cohort study. Setting The study setting area, Stockholm, Sweden, has a population of 2.3 million inhabitants, with seven emergency hospitals. Annually, approximately 210000 assignments are performed by 73 ambulances. All ambulance assignments performed from 1 January to 31 December 2015 were included.

Results In total, 23603 ambulance assignments ended in non-conveyance- $13.8 \%$ of all ambulance assignments performed in 2015. Compared with conveyed patients, non-conveyed patients were younger and more often female (median age 50.1 years for non-conveyed vs 61.7 years for conveyed; female $=52 \%$, both $p$ values $<0.001$ ). Approximately half of all ambulance assignments ending in non-conveyance were initially prioritised and dispatched as the highest priority. Non-conveyed patients were more often assessed by ambulance clinicians as presenting non-specific symptoms or symptoms related to psychiatric problems. Low blood glucose levels were highly associated with non-conveyance (adjusted OR (AOR): 15; $95 \%$ $\mathrm{Cl} 11.18$ to 20.13), although non-conveyed patients presented abnormal vital signs across all categories of vital signs. Moreover, drugs were more often administered to younger non-conveyed patients. Older patients were more often conveyed and administered drugs once conveyed (AOR: $1.29 ; 95 \% \mathrm{Cl} 1.07$ to 1.56 ).

Conclusions This study shows that non-conveyed patients represent a non-negligible proportion of all patients in contact with ambulance services. In general, most cases of non-conveyance occur at the highest dispatch level, to a large extent involve younger patients, and features problems assessed by ambulance clinicians as non-specific or related to psychiatric symptoms.

\section{INTRODUCTION}

Non-conveyed patients represent a significant and increasing proportion $(3.7 \%-93.7 \%)$, of all patients cared for by ambulance services

\section{Strengths and limitations of this study}

This large population-based cohort study involved data covering a whole year and the total ambulance patient cohort, thus offering a more nuanced picture of non-conveyance.

- Access to data covering the total ambulance patient cohort enabled the use of a comparison group, thus strengthening the statistical analyses conducted.

- This is one of few studies reporting vital signs in relation to non-conveyance.

- A main limitation is the retrospective nature of the study design, the use of medical records and patient data affected the availability of data.

in the western world. ${ }^{1-4}$ Non-conveyance has progressed as a result of a transformation on a systematic level; currently, ambulance services provide care that includes alternative care pathways, excluding the emergency department (ED) as the default final destination. ${ }^{5}$ The general non-conveyance population involves patients ranging from young to old, with a relatively even distribution of sex and a broad range of different initial problems. ${ }^{2}$ Non-conveyed patients have been shown to have an increased risk for subsequent adverse events, such as ED visits, hospital admission and even death, compared with patients who had been conveyed and discharged from EDs. ${ }^{6}$ Research has shown that conducting a non-conveyance assessment carries several challenging clinical paradoxes and is perceived to be a difficult task by ambulance clinicians. ${ }^{7}$ However, comparisons between different ambulance services are problematic due to an absence of definitions related to the non-conveyance cohort, the use of different research approaches, the lack of explicit national non-conveyance guidelines, differences in ambulance clinicians' competencies and the use of different triage tools. ${ }^{68}$ Regardless of which triage tool is used, assessment of vital signs is a fundamental part of 
all triage tools. ${ }^{9}$ Interestingly, approximately $60 \%$ of nonconveyed patients have been shown to present at least one abnormal vital sign at the time of the non-conveyance assessment $^{3}$; however, there is limited number of studies reporting vital signs among non-conveyed patients. ${ }^{2}$ The sparseness of overall knowledge on non-conveyance is problematic, as there is limited access to and use of valid non-conveyance guidelines among western ambulance services. ${ }^{2}$ Furthermore, these assessments are related to feelings of greater responsibility among clinicians. ${ }^{10}$ Knowledge of vital signs among non-conveyed patients seems to be important for the development of non-conveyance guidelines that reflect the clinical reality. ${ }^{2}$ Therefore, to increase knowledge regarding nonconveyed patients, the specific aims of the present study were, in the total cohort of ambulance assignments, to describe the prevalence of non-conveyance, investigate associations and compare patients' characteristics, drug administration, initial problems and vital signs between non-conveyed and conveyed patients.

The definition of non-conveyance within the ambulance service used by the National Health Service in England was applied in this study, that is, 'a term used to describe a 999 call to the ambulance service that results in a decision not to transport the patient to a health-care facility'.

\section{METHODS \\ Design}

This population-based retrospective cohort study was conducted in Stockholm, Sweden, and complies with the guidelines for Strengthening the Reporting of Observational Studies in Epidemiology. ${ }^{11}$

\section{Setting}

The study setting, Stockholm, Sweden, has a population of 2.3 million inhabitants, with seven emergency hospitals. ${ }^{12}$ The regional County Council is responsible for ambulance services within the region of Stockholm. The service is tax funded and performed by three different companies. Annually, the ambulance service in the area performs approximately 210000 ambulance assignments. ${ }^{13}$ All assignments are dispatched through the regional emergency medical communication centre (EMCC), which is reached through the national emergency number 1-1-2. EMCC operators decide whether an ambulance is dispatched or not, based on a symptombased clinical decision support system called the Swedish Medical Index. ${ }^{14}$ If an ambulance was dispatched during the study period, the operator had three different priority levels to choose from: level 1 carried the highest priority, and level 3 the lowest. According to national regulations, every ambulance must be crewed by at least one registered nurse. ${ }^{15}$ Further, the Stockholm region additionally requires at least one of the two persons in the ambulance team to have 1 year's additional university training and a degree in specialist nursing. ${ }^{13}$ The specialist nurse takes medical responsibility within the ambulance team. ${ }^{16}$ Specialist nurse education have been shown to lack specific non-conveyance training. ${ }^{17}$ A triage tool, the Rapid Emergency Triage and Treatment System (RETTS $)^{18}$ is used by the majority of Swedish ambulance services and forms an obligatory part of all assessments according to regional guidelines. ${ }^{16}$ The RETTS assessment is based on patients' vital signs and chief problem, and generates one of four different priority levels (red, orange, yellow and green); red is the highest and green the lowest priority. Level green indicates unaffected vital signs and most often also absence of disease. ${ }^{18}$ The nonconveyance guideline in the study area is largely based on RETTS and stipulates that patients suitable for nonconveyance should be prioritised as level green. ${ }^{16}$

\section{Data collection}

The study period was from 1 January to 31 December 2015 and included all ambulance assignments performed in the region of Stockholm during this time. Each ambulance run is assigned a unique run number when dispatched by the EMCC, and data were collected from the ambulance medical record (CAK-net; Region Stockholm). Inclusion criteria were as follows: (1) ambulance assignments performed by emergency ambulances, that is, excluding physician-manned rapid response units, non-emergency ambulances and helicopters; (2) each ambulance run was classified as a primary ambulance run, that is, the patient had not been assessed by other registered healthcare personnel, as is the case with intrahospital transports; (3) the patient was not deceased at arrival of the ambulance; and (4) the patient was not unsuccessfully resuscitated and left at the scene (figure 1). The narrative text section in all ambulance medical records, written by ambulance clinicians, was excluded from our data extraction due to the great amount of included ambulance missions.

\section{Patient and public involvement}

There was no patient and/or public involvement in this study. The need for informed consent was waived by the The Regional Ethical Review Board of Stockholm. The final dataset was fully anonymised before analysis.

\section{Data analysis}

Several of the collected variables were stratified into categories. Sex was categorised into two groups (male and female), age was categorised into three groups $(<18$ years, 18-64 years and $>65$ years), EMCC-priority level was categorised into three groups (level 1 (highest priority), level 2 and level 3 (lowest priority)). Time of day was categorised based on the availability of primary care units and minor urgency departments in the region of Stockholm during the study period, generating three different time intervals (day, 08:00-16:00; evening, 16:01-22:00; and night, 22:01-07:59). The categorisation of geographical location was based on The Swedish Association of Local Authorities and Regions division of municipalities ${ }^{19}$ and generated four classifications (highly urban, urban, average 


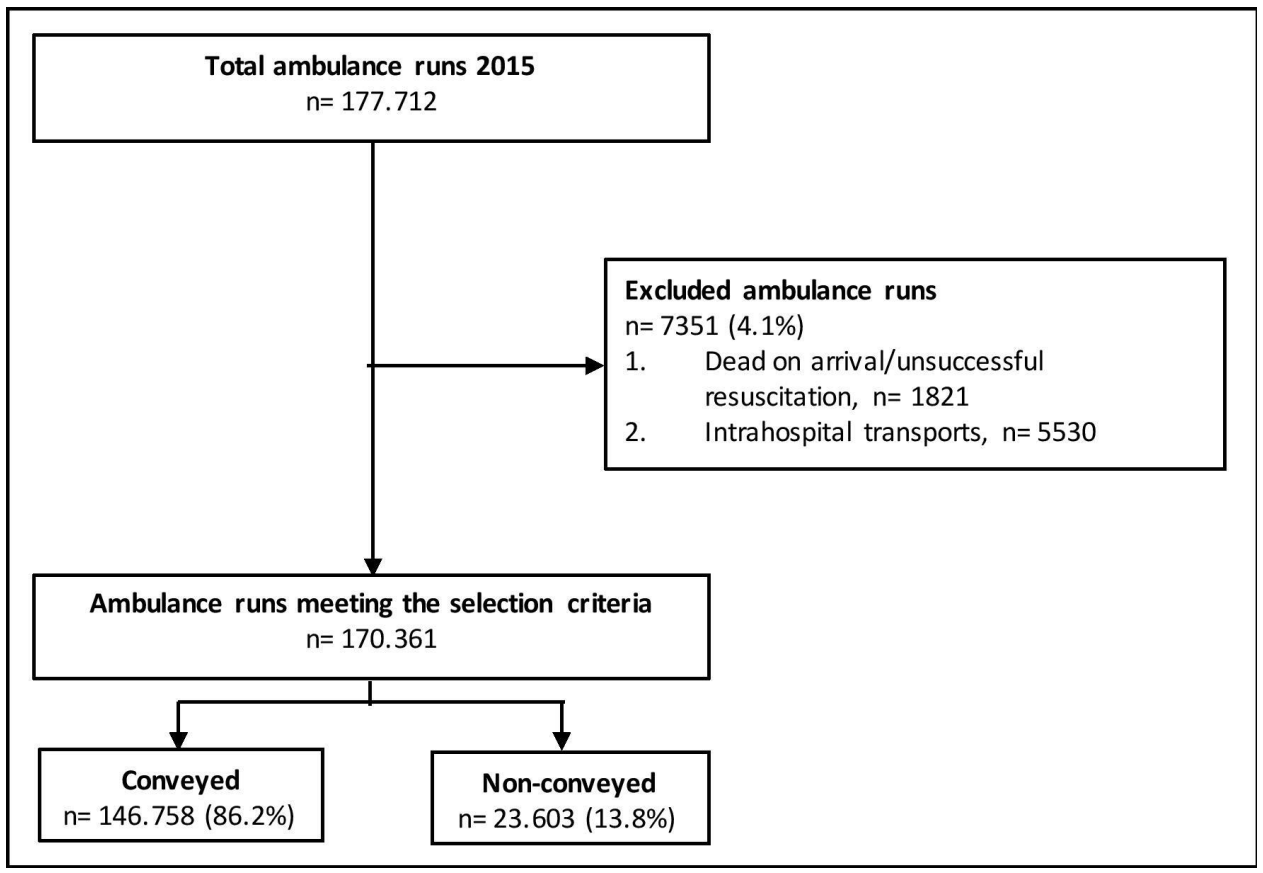

Figure 1 Flow chart over included and excluded ambulance assignments in Stockholm, Sweden, 2015.

urban and rural). The National Advisory Committee for Aeronautics (NACA) score,$^{20}$ where severity status is graded on an eight-level scale, with higher values indicating a more severe condition, was modified as a sevenlevel scale, excluding deceased patients. The on-scene triage level was categorised according to the RETTS, ${ }^{18}$ generating four groups (in decreasing order of priority: triage 1 , triage 2 , triage 3 and triage 4 ). Drugs administration was categorised as administered or not administered, and conveyance status was categorised as non-conveyed or conveyed. The prehospital initial assessment codes are registered by the ambulance clinician documenting the medical record, using a categorisation of medical conditions based on signs and symptoms. Originally, the dataset consisted of 140 different codes, these were aggregated into 10 categories (online supplementary file 1), and validity during the categorisation process was maintained through the use of the regional medical guidelines for the overall categorisation of signs and symptoms. ${ }^{16}$ This process was performed by JL with support by TD and VL, hence ensuring reliability. Cut-off points for vital signs were constructed for the different age groups, based on cut-off points used in the RETTS. ${ }^{18}$ Each category of vital signs consisted of three groups (normal, abnormal-too high, and abnormal-too low), except for oxygen saturation level and Glasgow Coma Scale, which were divided into two groups (normal and abnormal; online supplementary file 1).

\section{Statistical analysis}

Differences in characteristics between the non-conveyed and conveyed patients were analysed using $\chi^{2}$ tests, Cramer's V-tests and t-tests where applicable, with the significance level set at 0.05 . Multiple logistic regression analyses were performed using two models; non-conveyance was set as the outcome for both models. The first model investigated possible associations with prehospital initial assessment codes and the second model involved vital signs. Goodness of fit for each model was evaluated using the Hosmer-Lemeshow test and the AUC, respectively. Unadjusted ORs and adjusted ORs with 95\% CIs were calculated. Both models were adjusted for the following variables: sex, age, EMCC-priority level, time of day, geographical location, drugs administered, actions taken, day of week, NACA score and on-scene triage level. Data were analysed using STATA V.15.1 (StataCorp. 2017. Stata Statistical Software: Release 15. College Station, Texas: StataCorp LLC).

\section{RESULTS}

\section{Characteristics of non-conveyed patients}

In total, 23603 ambulance assignments ended in nonconveyance-13.8\% of all assignments performed in 2015. Overall, non-conveyed patients were younger and more often female compared with conveyed patients (median age for non-conveyed 50.1 vs 61.7 for conveyed, and $52 \%$ female non-conveyed, both $\mathrm{p}$ values $<0.001$; table 1). In comparison to the conveyance group which had higher prevalence during daytime, there was a relatively even distribution for time of day ambulance assignments ending in non-conveyance-approximately one-third during day, evening and night, respectively $(p<0.001$; table 1$)$. Approximately half of all ambulance assignments ending in non-conveyance were initially prioritised and dispatched as the highest priority by the EMCC. Similar figures were found among the conveyance group. The majority of all non-conveyed patients were assessed to be at the lowest on-scene triage level (70.4\%), 
Table 1 Differences in characteristics between non-conveyed and conveyed patients

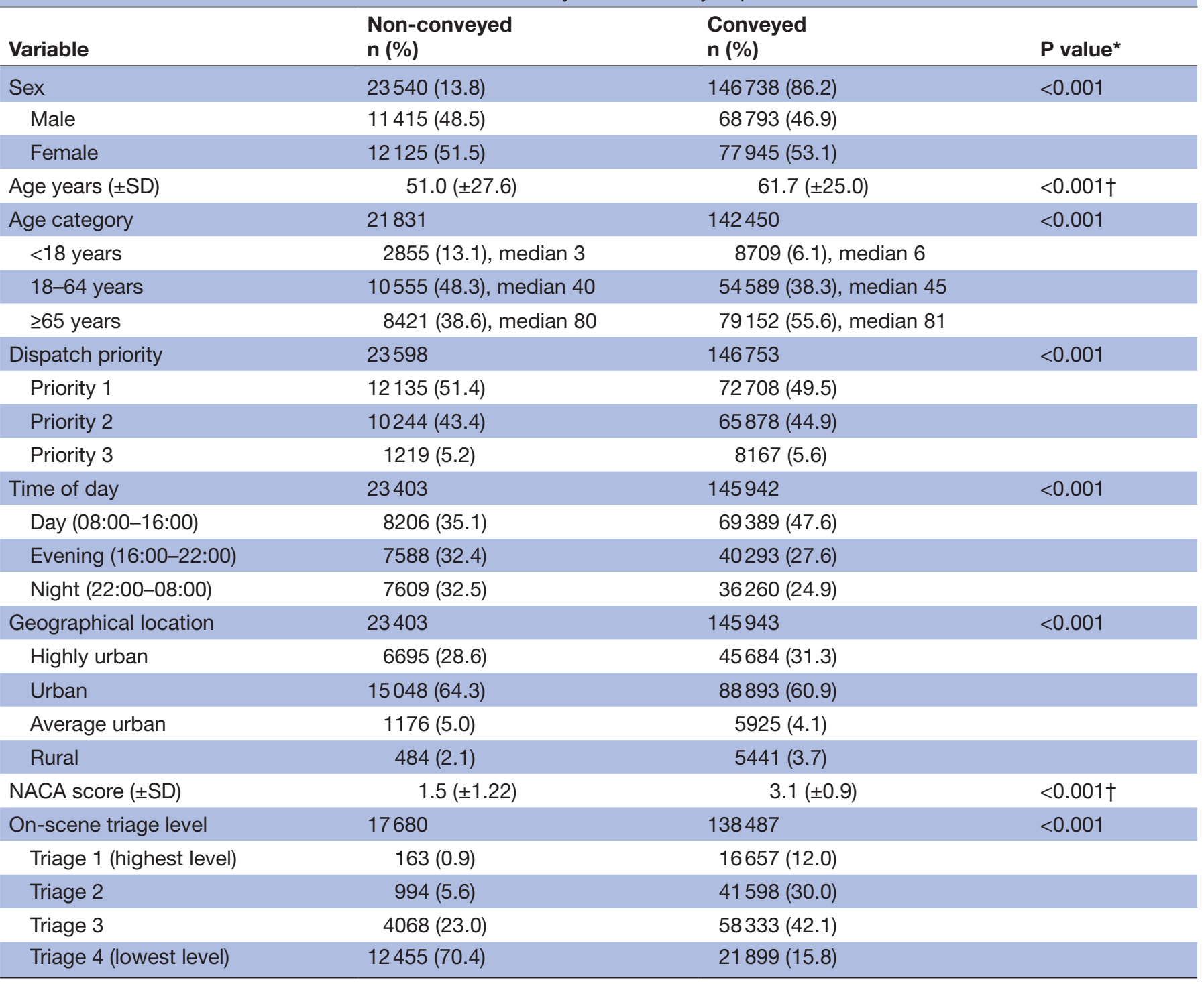

${ }^{*} \chi^{2}$ test.

tt-test.

NACA, National Advisory Committee for Aeronautics.

although non-conveyed patients were observed across all four on-scene triage levels. Conveyed patients were more often triaged among the mid-high on-scene triage levels, and in less extent at the lowest triage level $(p<0.001$; table 1).

\section{Characteristics of prehospital initial assessment codes}

The range of prehospital initial assessment codes among non-conveyed patients covered all 10 categories (table 2). Moreover, the top three most common assessment codes among non-conveyed patients were 'Other/Nonclassifiable symptoms' (26.4\%), 'Nervous symptoms' (20.1 $\%)$, and 'Trauma' (13.9\%). Among conveyed patients the codes 'Nervous symptoms' (20.4\%), 'Trauma' (20.3 $\%$ ), and 'Digestive and abdominal symptoms' (13.0\%; table 2) were most commonly used. Symptoms classified as 'Psychiatric symptoms' were in greater extent than others associated with non-conveyance (AOR: 4.05; $95 \%$ CI 3.62 to 4.53 ; table 3). Younger and adult non-conveyed patients were more often administered drugs $(14.8 \%$ and $46.8 \%$, respectively, $\mathrm{p}<0.001$; table 2 ). Older patients were more often conveyed and administered drugs once conveyed (AOR: 1.29; $95 \%$ CI 1.07 to 1.56 ; table 3).

\section{Characteristics of vital signs}

Abnormal vital signs among non-conveyed patients were found for all categories of vital signs (table 4). Patients having at least one registered abnormal vital sign was less prevalent among non-conveyed patients compared with conveyed patients $(32.1 \%$ and $59.3 \%$, respectively, $\mathrm{p}<0.001$; table 4$)$. The difference of having at least one registered abnormal vital sign was smaller among younger patients $(29.3 \%$ and $50.2 \%$, respectively; $\mathrm{p}<0.001)$ than older patients (table 4). Among non-conveyed patients, 
Table 2 Differences in prehospital initial assessment codes and drug administration between non-conveyed and conveyed patients

\begin{tabular}{llcr}
\hline Variable & $\begin{array}{l}\text { Non-conveyed } \\
\mathbf{n}(\%)\end{array}$ & $\begin{array}{l}\text { Conveyed } \\
\mathbf{n}(\%)\end{array}$ & P value* $^{*}$ \\
\hline Prehospital Initial Assessment Code $(\mathrm{n})$ & 23603 & 146756 & \\
\hline Other/non-classifiable symptoms & $6224(26.4)$ & $12529(8.5)$ & $<0.001$ \\
\hline Nervous symptoms & $4753(20.1)$ & $29959(20.4)$ & 0.327 \\
\hline Trauma & $3288(13.9)$ & $29754(20.3)$ & $<0.001$ \\
\hline Respiratory symptoms & $1913(8.1)$ & $16316(11.1)$ & $<0.001$ \\
\hline Psychiatric symptoms & $1826(7.7)$ & $2705(1.8)$ & $<0.001$ \\
\hline Digestive and abdominal symptoms & $1758(7.5)$ & $19017(13.0)$ & $<0.001$ \\
\hline Circulatory symptoms & $1466(6.2)$ & $18951(12.9)$ & $<0.001$ \\
\hline Medical symptoms & $1226(5.2)$ & $7219(4.9)$ & 0.071 \\
\hline Infectious symptoms & $1063(4.5)$ & $8450(5.8)$ & $<0.001$ \\
\hline Obstetrics and gynaecological symptoms & $86(0.4)$ & $1856(1.3)$ & $<0.001$ \\
\hline Drugs administered (n) & 4321 & 50766 & $<0.001$ \\
\hline <18years & $639(14.8)$ & $3193(6.3)$ & \\
18-64years & $2021(46.8)$ & $18529(36.5)$ & \\
\hline 65years & $1661(38.4)$ & $29044(57.2)$ & \\
\hline
\end{tabular}

Descending order following prehospital initial assessment codes for non-conveyed patients.

${ }^{*} \chi^{2}$ test.

'Low blood sugar level' (5.6\% and $0.6 \%$, respectively; $\mathrm{p}<0.001)$ and 'Too low respiratory rate' $(0.6 \%$ and $0.4 \%$, respectively; $\mathrm{p}<0.001$; table 4 ) were more common. The odds of an ambulance run ending in non-conveyance was 15 (95\% CI 11.18 to 20.13 ; table 5 ) if a patient was registered with 'Low blood sugar level'.

Table 3 Unadjusted and adjusted ORs (AORs) for prehospital initial assessment codes and drug administration for nonconveyed and conveyed patients

\begin{tabular}{|c|c|c|c|c|}
\hline \multirow[b]{2}{*}{ Variable } & \multicolumn{2}{|l|}{ Non-conveyed } & \multicolumn{2}{|l|}{ Conveyed } \\
\hline & Unadj OR (95\% Cl) & Adj OR $(95 \% \mathrm{Cl})^{\star}$ & Unadj OR $(95 \% \mathrm{Cl})$ & Adj OR $(95 \% \mathrm{Cl})^{*}$ \\
\hline Prehospital Initial Assessment Code (n) & 170359 & 150603 & 170359 & 150603 \\
\hline Trauma & 1 (ref) & 1 (ref) & 1 (ref) & 1 (ref) \\
\hline Psychiatric symptoms & 6.11 (5.70 to 6.55$)$ & 4.05 (3.62 to 4.53 ) & $0.16(0.15$ to 0.18$)$ & $0.25(0.22$ to 0.28$)$ \\
\hline Nervous symptoms & 1.44 (1.37 to 1.51$)$ & 1.83 (1.70 to 1.97$)$ & 0.70 (0.66 to 0.73$)$ & $0.55(0.51$ to 0.59$)$ \\
\hline Infectious symptoms & 1.14 (1.06 to 1.22$)$ & 1.80 (1.61 to 2.01$)$ & 0.88 (0.82 to 0.95$)$ & $0.56(0.50$ to 0.62$)$ \\
\hline Other/non-classifiable symptoms & $4.50(4.29$ to 4.71$)$ & 1.50 (1.39 to 1.62$)$ & $0.22(0.21$ to 0.23$)$ & $0.67(0.62$ to 0.72$)$ \\
\hline Respiratory symptoms & $1.06(0.99$ to 1.13$)$ & 1.49 (1.36 to 1.64$)$ & 0.94 (0.89 to 1.00$)$ & $0.67(0.61$ to 0.73$)$ \\
\hline Medical symptoms & $1.54(1.43$ to 1.65$)$ & 1.25 (1.13 to 1.40$)$ & 0.65 (0.61 to 0.70$)$ & $0.80(0.72$ to 0.89$)$ \\
\hline Circulatory symptoms & 0.70 (0.66 to 0.75$)$ & 1.21 (1.11 to 1.33$)$ & 1.43 (1.34 to 1.52$)$ & $0.82(0.75$ to 0.90$)$ \\
\hline Digestive and abdominal symptoms & 0.84 (0.79 to 0.89$)$ & 0.97 (0.89 to 1.06$)$ & $1.20(1.12$ to 1.27$)$ & $1.03(0.94$ to 1.12$)$ \\
\hline Obstetrics and gynaecological symptoms & $0.42(0.34$ to 0.52$)$ & 0.34 (0.25 to 0.47$)$ & 2.38 (1.92 to 2.97$)$ & $2.91(2.11$ to 4.01$)$ \\
\hline Drugs administered (n) & 55087 & $51388 \dagger$ & 55087 & $51388 \dagger$ \\
\hline$<18$ years & 1.83 (1.67 to 2.02$)$ & 1.18 (0.95 to 1.47$)$ & 0.55 (0.49 to 0.60$)$ & 0.85 (0.68 to 1.06$)$ \\
\hline 18-64 years & 1 (ref) & 1 (ref) & 1 (ref) & 1 (ref) \\
\hline$\geq 65$ years & $0.52(0.49$ to 0.56$)$ & 0.77 (0.64 to 0.94$)$ & 1.91 (1.78 to 2.04$)$ & $1.29(1.07$ to 1.56$)$ \\
\hline
\end{tabular}

Descending order following prehospital initial assessment codes AOR for non-conveyed patients.

${ }^{*}$ Adjusted for sex, age, dispatch priority, time of day, location, drugs administered, actions taken, day of week, National Advisory Committee for Aeronautics (NACA) score and on-scene triage level.

†Adjusted for sex, age, dispatch priority, time of day, location, actions taken, day of week, NACA score and on-scene triage level. 
Table 4 Differences in vital signs between non-conveyed and conveyed patients

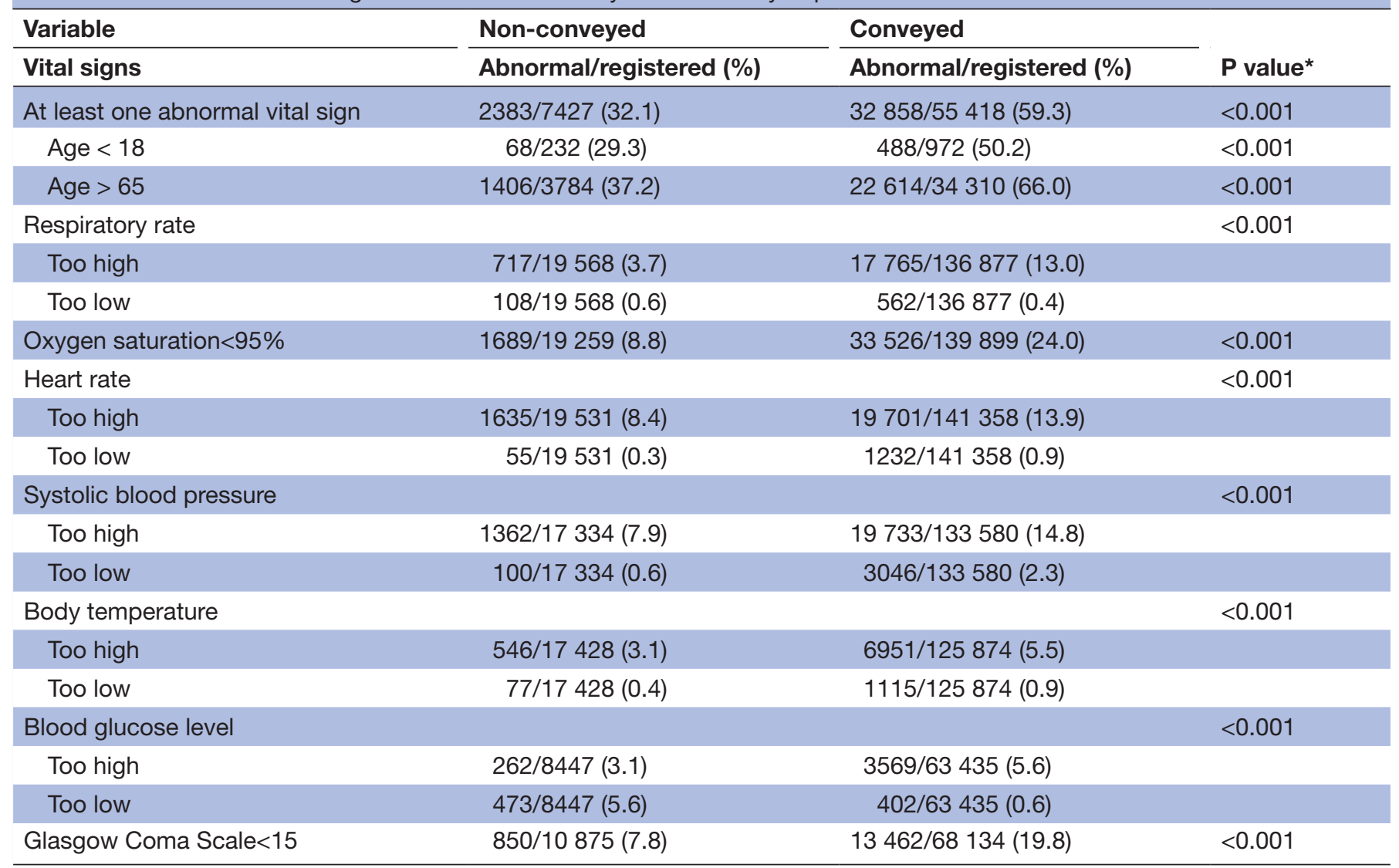

${ }^{*} \chi^{2}$ test.

\section{DISCUSSION}

The results of this large population-based retrospective cohort study show that non-conveyed patients differ on several aspects in comparison to conveyed patients. Nonconveyance generally occurs at the highest dispatch level, involves younger patients and often involves problems assessed by ambulance clinicians as non-specific or related to psychiatric problems. Low blood glucose levels are highly associated with non-conveyance, although nonconveyed patients presented abnormal vital signs among all possible categories of vital signs. Moreover, a higher incidence of administered drugs was observed among young and adult non-conveyed patients.

In total, $13.8 \%$ of all ambulance runs performed in the study setting area during 2015 ended in non-conveyance. This figure can be placed in the lower bound of the nonconveyance range for the general non-conveyance population as previous described in literature. ${ }^{2}$ Both internal and external factors have been shown to influence ambulance services non-conveyance rates. Ambulance service senior managements attitude towards non-conveyance have been shown to influence non-conveyance rates, if it is considered as a risky endeavour or an opportunity. ${ }^{21}$ Perceived limited support from ambulance management regarding non-conveyance has earlier been described by clinically active ambulance clinicians in this paper's study setting area. ${ }^{7}$ This could possibly explain the lower non-conveyance rates seen in this paper compared with other non-conveyance rates in western ambulance services.

The relatively even sex distribution found in our study is supported by previous non-conveyance research. ${ }^{23}$ The age distribution, specifically the significantly lower age of non-conveyed patients, is also supported by the findings of other studies, ${ }^{3}{ }^{22} 23$ possibly indicating correspondence between increasing age and the need for conveyance, as well as need of further medical interventions or examinations at the ED. However, a relatively large proportion of all non-conveyed patients in our cohort were either young or old; both these groups have previously been described as vulnerable in a non-conveyance context. ${ }^{2}$ One unanticipated finding was the big proportion of children among the non-conveyance population. Possible misclassification of exposure could be one explanation behind these high figures; patients who were conveyed to the ED by own transport, such as parents with young children, could not be identified in our dataset and could therefore have been misclassified as non-conveyed. The highest dispatch level represented the majority of all ambulance assignments ending with non-conveyance. Earlier findings have indicated comparable results, ${ }^{23}$ though not to the same extent as ours. Similar dispatch level figures were seen among conveyed patients also. Ambulance assignments dispatched as the highest priority have generally 
Table 5 Unadjusted and adjusted ORs for abnormal vital signs for non-conveyed and conveyed patients

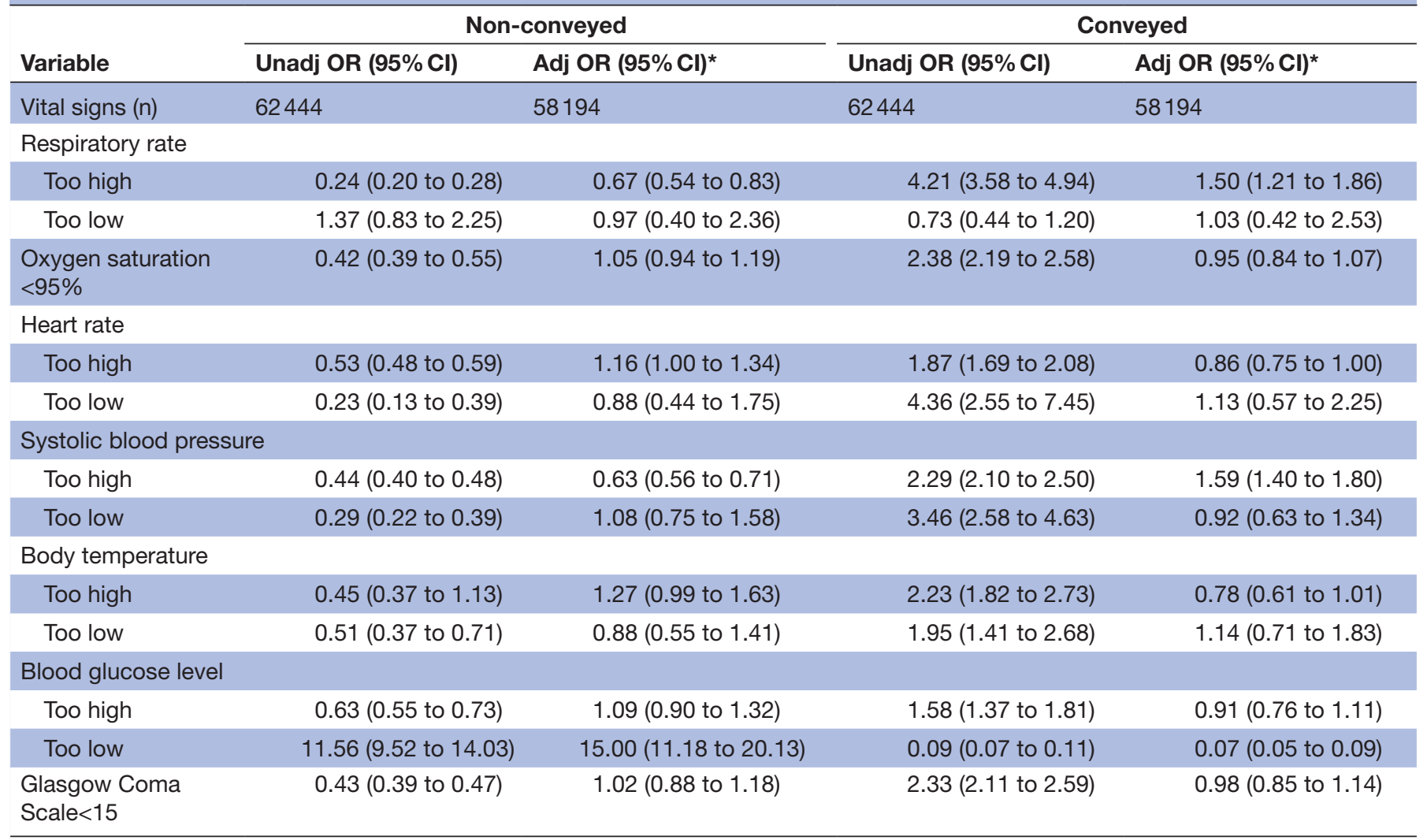

${ }^{*}$ Adjusted for sex, age, dispatch priority, time of day, location, drugs administered, actions taken, day of week, National Advisory Committee for Aeronautics score and on-scene triage level.

continued to increase for all ambulance assignments in the study setting area in the years following $2015 .^{13}$ Accuracy between dispatch priority level and the patient's medical needs is considered crucial to the optimisation of ambulance resources. ${ }^{24}$ Hypoglycaemia is an example of a condition where it is possible for ambulance clinicians to complete on-site treatment and discharge at scene, ${ }^{25}$ but the condition often requires the highest dispatch level. However, the number of hypoglycaemia cases in the study population does not fully explain the high proportion of the highest dispatch level among non-conveyed patients and it is therefore of interest, from both patient safety and ambulance availability perspectives, to further investigate non-conveyance with a focus on specificity and sensitivity of the EMCC assessments.

As too our knowledge, this is the first paper investigating drugs administration and non-conveyance. A higher incidence of administered drugs was observed among young and adult non-conveyed patients compared with conveyed patients. Increasing age in combination with drugs administration was associated with conveyance. These findings call for further investigation focusing on drug administration and non-conveyance, and possible association with adverse patient outcome.
Surprisingly, we found that non-conveyance had an even distribution across time of day, in contrast with conveyed patients, who had a higher prevalence during daytime. Ambulance clinicians have previously expressed a need for support from the wider healthcare system, such as primary care, to achieve a satisfying level of patient safety and their own sense of security when conducting non-conveyance assessments. ${ }^{7}$ Our finding encourages future studies investigating patient outcome following non-conveyance.

All 10 categories of initial assessment codes were represented among the non-conveyance group, which is comparable with previous studies. ${ }^{13}$ Our results, however, show a higher number of non-specific problems within the non-conveyance group than previously reported. ${ }^{23}$ Patients with psychiatric symptoms have generally been more common among the non-conveyance group ${ }^{1326}$; however, in our study, they were represented to a greater extent. Both patients with non-specific problems and patients with psychiatric symptoms were more common among non-conveyance compared with conveyance have; these two patient groups have previously been described as vulnerable ${ }^{26}$ and patients with non-specific problems have been shown to have a greater risk of mortality once 
presented at the ED. ${ }^{27}$ Furthermore, older patients are most often over-represented among this group of patients, and specialist nurse training curricula have been found to lack training in non-conveyance assessments, ${ }^{17}$ raising questions regarding clinicians' knowledge base for conducting non-conveyance assessments involving vulnerable patients. Prehospital initial assessment codes more common among the conveyed group were 'Nervous symptoms', 'Trauma' and 'Digestive and abdominal symptoms'. One possible explanation is that these problems may require further diagnostics by examinations conducted at the ED. Comparisons with the results from previous studies should be done with caution due to differences in the categorisation of problems and initial assessment codes.

Approximately one-third of all non-conveyed patients had at least one registered abnormal vital sign; this number increased among younger patients and decreased among older patients. All vital signs differed between the two groups, although 'Too low respiratory level' and 'Too low blood sugar level' were more common among nonconveyed patients. In this regard, our study contributes to the relatively few previous studies reporting vital signs in relation to non-conveyance. Furthermore, our findings support the findings of other studies linking abnormal vital signs to non-conveyance. ${ }^{2}$ The overall prevalence of abnormal vital signs among non-conveyed patients in our study is higher than in previous studies, ${ }^{65}$ though still smaller than recently published results from The Netherlands. ${ }^{3}$ Vital signs are widely used in different triage tools, often considered important and fundamental. Abnormal vital signs might be a good indicator of deterioration in patients who are already in critical conditions, ${ }^{28}$ but it does not work as well for patients with still unaffected vital functions, ${ }^{29}$ such as most patients suitable for nonconveyance. Furthermore, abnormal vital signs may not be present among older patients, despite the presence of a serious condition. ${ }^{30}$ However, the current study does not relate abnormal vital signs to poor patient outcome, which is important for reaching reliable results regarding abnormal vital signs and non-conveyance.

\section{LIMITATIONS}

The use of medical records comes with several challenges as the data were not gathered for research purposes in the first place; this might explain the variations in data availability in our material. Generally, there were missing data for all included variables, which affects the current study's internal validity. Further, the medical records did not include information on whether a patient had been referred to a primary care unit or elsewhere ('see and refer'). In addition, the exclusion of the narrative text section in the medical records limits this paper to be of a narrower biomedical perspective. Other potentially important aspects influencing the ambulance clinician's decision-making process, such as holistic consideration of patients' well-being, uncertainty of personal liability and internal organisational performance regimes focusing on conveyance, might be underplayed by the exclusion of the narrative text section in the medical records. The third limitation relates to the current study's external validity, affected by our use of prehospital initial problems codes. These codes are valid across Sweden, but might have limited validity among other EMS systems. Furthermore, we did not investigate patient outcome following the non-conveyance decision, which limits our findings to serve a descriptive purpose only, and we cannot conclude whether any adverse events could be related to specific patient demographics or characteristics. Future research ought to focus on investigating and evaluating relevant outcome measures with the aim to enable follow-up from a patient safety perspective among the non-conveyance population.

\section{CONCLUSION}

In conclusion, the current study shows that non-conveyed patients represent a non-negligible proportion of all patients in contact with ambulance services. In general, most cases of non-conveyance occur at the highest dispatch level, to a greater extent involves younger patients and problems assessed by ambulance clinicians as non-specific or related to psychiatric symptoms. Drugs are administered mostly to younger non-conveyed patients, and a relatively large proportion of non-conveyed patients present abnormal vital signs; low blood glucose levels were highly associated with non-conveyance.

\section{Author affiliations}

${ }^{1}$ Department of Clinical Science and Education, Södersjukhuset, Karolinska Institutet, Stockholm, Sweden

${ }^{2}$ Academic Emergency Medical Services, Stockholm, Sweden

${ }^{3}$ Department of Neurobiology, Care Sciences and Society, Section of Nursing, Karolinska Institutet, Stockholm, Sweden

${ }^{4}$ Samariten Ambulance, Stockholm, Sweden

${ }^{5}$ Department of Health and Caring Sciences, Faculty of Health and Life Sciences, Linnaeus University, Växjö, Sweden

${ }^{6}$ Centre of Interprofessional Cooperation within Emergency care, Faculty of Health and Life Sciences, Linnaeus University, Växjö, Sweden

${ }^{7}$ Department of Health Promoting Science, Sophiahemmet University College, Stockholm, Sweden

${ }^{8}$ Department of Medicine, Solna, Karolinska Institutet, Stockholm, Sweden

Acknowledgements The authors would like to thank Academic EMS Stockholm for support. They would also like to thank Veronica Vicente, AISAB (Ambulance care in Greater Stockholm Ltd), for support with the data extraction.

Contributors All authors contributed during the planning stage. JL performed the data collection and the data analysis. TD and VL supported the data analysis and the interpretation of data. CE and CL collaborated with the other authors in discussing and establishing the results. All authors contributed, read and approved the final manuscript.

Funding This work was supported by Region Stockholm through Academic Emergency Medical Services Stockholm.

Competing interests None declared.

Patient consent for publication Not required.

Ethics approval The Regional Ethical Review Board of Stockholm approved this study (2017/2187-31).

Provenance and peer review Not commissioned; externally peer reviewed. 
Data availability statement Data are available upon reasonable request. Data may be obtained from a third party and are not publicly available. The data that support the findings of this study are available from the respective ambulance companies, but restrictions apply to the availability of these data, which were used under license for the current study, and so are not publicly available. Deidentified participant data are however available from the authors upon reasonable request and with permission of the respective ambulance company.

Open access This is an open access article distributed in accordance with the Creative Commons Attribution Non Commercial (CC BY-NC 4.0) license, which permits others to distribute, remix, adapt, build upon this work non-commercially, and license their derivative works on different terms, provided the original work is properly cited, appropriate credit is given, any changes made indicated, and the use is non-commercial. See: http://creativecommons.org/licenses/by-nc/4.0/.

\section{ORCID iD}

Jakob Lederman http://orcid.org/0000-0001-9180-161X

\section{REFERENCES}

1 Ebben RHA, Castelijns M, Frenken J, et al. Characteristics of non-conveyance ambulance runs: a retrospective study in the Netherlands. World J Emerg Med 2019;10:239-43.

2 Ebben RHA, Vloet LCM, Speijers RF, et al. A patient-safety and professional perspective on non-conveyance in ambulance care: a systematic review. Scand J Trauma Resusc Emerg Med 2017;25:71.

3 Vloet LCM, de Kreek A, van der Linden EMC, et al. A retrospective comparison between non-conveyed and conveyed patients in ambulance care. Scand J Trauma Resusc Emerg Med 2018;26:91.

4 O'Cathain A, Knowles E, Bishop-Edwards L, et al. Understanding variation in ambulance service non-conveyance rates: a mixed methods study. Health Serv Deliv Res 2018;6:1-192.

5 Lindström V, Bohm K, Kurland L. Prehospital care in Sweden. notfall + rettungsmedizin. Springer Berlin Heidelberg, 2015. http://link. springer.com/

6 Tohira H, Fatovich D, Williams TA, et al. Is it appropriate for patients to be discharged at the scene by Paramedics? Prehosp Emerg Care 2016;20:539-49.

7 Lederman J, Löfvenmark C, Djärv T, et al. Assessing nonconveyed patients in the ambulance service: a phenomenological interview study with Swedish ambulance clinicians. BMJ Open 2019;9:e030203-8.

8 Yeung T, Shannon B, Perillo S, et al. Review article: outcomes of patients who are not transported following ambulance attendance: a systematic review and meta-analysis. Emerg Med Australas 2019;31:321-31.

9 Farrohknia N, Castrén M, Ehrenberg A, et al. Emergency department triage scales and their components: a systematic review of the scientific evidence. Scand J Trauma Resusc Emerg Med 2011;19:42.

10 Höglund E, Schröder A, Möller M, et al. The ambulance nurse experiences of non-conveying patients. J Clin Nurs 2019;28:235-44.

11 von Elm E, Altman DG, Egger M, et al. The strengthening the reporting of observational studies in epidemiology (STROBE) statement: guidelines for reporting observational studies. Int J Surg 2014;12:1495-9.

12 Stockholm County Council. Patienttransporter I framtidens hälso-och sjukvård, 2016. Available: http://www.sll.se/Global/Om landstinget/ Så granskas landstinget/Projektrapporter/Rapporter-2016/Rapport7-2016-RK-201604-0024.pdf
13 Stockholm County Council. Årsrapport 2018 Prehospitala verksamheter i Stockholms läns landsting [Anual report 2018 Prehospital units in the Stockholm County Council], 2018. Available: internal-pdf://248.246.30.180/prehospital vård i sll 2015-03-18.pdf

14 SOS-Alarm. Patientsäkerhetsberättelse [Annual patient safety report], 2019.

15 The National Board of Health and Welfare. Socialstyre/sens föreskrifter om ambulanssjukvård $\mathrm{mm}$ [The National Board of Health and Welfare's regulations ambulance]. Stockholm: The National Board of Health and Welfare, 2009.

16 Stockholm County Council. Medicinska riktlinjer för ambulanssjukvården[Medical guidelines for the ambulance service]. Stockholm: Stockholm County Council, 2017.

17 Sjölin $\mathrm{H}$, Lindström V, Hult $\mathrm{H}$, et al. What an ambulance nurse needs to know: a content analysis of curricula in the specialist nursing programme in prehospital emergency care. Int Emerg Nurs $2015 ; ; 23: 127-32$.

18 Widgren BR, Jourak M. Medical emergency triage and treatment system (METTS): a new protocol in primary triage and secondary priority decision in emergency medicine. J Emerg Med 2011;40:623-8

19 Swedish Association of Local Authorities and Regions. Classification of Swedish municipalities, 2017.

20 Raatiniemi L, Mikkelsen K, Fredriksen K, et al. Do pre-hospital anaesthesiologists reliably predict mortality using the NACA severity score? A retrospective cohort study. Acta Anaesthesiol Scand 2013;57:1253-9.

21 Knowles E, Bishop-Edwards L, O'Cathain A. Exploring variation in how ambulance services address non-conveyance: a qualitative interview study. BMJ Open 2018;8:e024228.

22 Magnusson CR, Källenius CR, Knutsson SR, et al. Pre-hospital assessment by a single responder: the Swedish ambulance nurse in a new role: a pilot study, 2016. Available: http://ac.els-cdn.com. proxy.kib.ki.se/S1755599X15000907/1-s2.0-S1755599X15000907main.pdf?_tid=50d2140e-9d07-11e7-89f7-00000aacb361\&acdnat= 1505804220_cbd5368c4009bbe3f5797ed886d3ba32 [Accessed 19 Sept 2017].

23 Norberg G, Wireklint Sundström B, Christensson L, et al. Swedish emergency medical services' identification of potential candidates for primary healthcare: Retrospective patient record study. Scand J Prim Health Care 2015;33:311-7.

24 Dami F, Golay C, Pasquier M, et al. Prehospital triage accuracy in a criteria based dispatch centre. BMC Emerg Med 2015;15:1-9.

25 Tohira H, Fatovich D, Williams TA, et al. Paramedic checklists do not accurately identify post-ictal or hypoglycaemic patients suitable for discharge at the scene. Prehosp Disaster Med 2016;31:282-93.

26 Breeman W, Poublon NA, Verhofstad MHJ, et al. Safety of onscene medical care by EMS nurses in non-transported patients: a prospective, observational study. Scand J Trauma Resusc Emerg Med 2018;26:1-9.

27 Djärv T, Castrén M, Mårtenson L, et al. Decreased general condition in the emergency department. Eur J Emerg Med 2015;22:241-6.

28 Barfod C, Lauritzen MMP, Danker JK, et al. Abnormal vital signs are strong predictors for intensive care unit admission and inhospital mortality in adults triaged in the emergency department - a prospective cohort study. Scand J Trauma Resusc Emerg Med 2012;20:28

29 Kline JA, Corredor DM, Hogg MM, et al. Normalization of vital signs does not reduce the probability of acute pulmonary embolism in symptomatic emergency department patients. Acad Emerg Med 2012;19:11-17.

30 Chester JG, Rudolph JL. Vital signs in older patients: age-related changes. J Am Med Dir Assoc 2011;12:337-43. 